\title{
Inoculação com Azospirillum brasilense para a produção de milho para silagem
}

\author{
Inoculation with Azospirillum brasilense for the production of maize for silage \\ Inoculación con Azospirillum brasilense para la producción de maíz para ensiladoy
}

Recebido: 25/01/2022 | Revisado: 30/01/2022 | Aceito: 06/02/2022 | Publicado: 12/02/2022

Kelly Cristina Camargo

ORCID: https://orcid.org/0000-0002-6779-2271

Universidade Estadual do Rio Grande do Sul, Brasil E-mail: kelly-camargo@uergs.edu.br

Biane Castro

ORCID: https://orcid.org/0000-0002-9356-8003 Universidade Estadual do Rio Grande do Sul, Brasil E-mail: biane-castro@uergs.edu.br

Leonardo de Melo Menezes

ORCID: https://orcid.org/0000-0001-8536-0803 Universidade Estadual do Rio Grande do Sul, Brasil E-mail: leonardo-menezes@uergs.edu.br

Marlo Markus Lopes

ORCID: https://orcid.org/0000-0002-1294-758X Emater/RS-Ascar, Brasil

E-mail: marlomarkus@hotmail.com

\begin{abstract}
Resumo
A adubação nitrogenada tem papel fundamental para a determinação da produtividade e rentabilidade da cultura do milho. O gênero Azospirillum possui a capacidade, quando associado com as gramíneas, de fixar o nitrogênio atmosférico e prover reguladores de crescimento. Este trabalho teve como objetivo avaliar o efeito da inoculação de Azospirillum brasilense nas sementes de milho cultivado para a produção de silagem em Santana do Livramento, RS. Os tratamentos consistiram em comparar plantas de milho para a produção de silagem com e sem inoculação na semeadura das cepas AbV5 e AbV6 de Azospirillum brasilense, na concentração de 2x10 ${ }^{8} \mathrm{UFC} \mathrm{ml}^{-1}$. Foram analisados, a partir de 20 repetições por tratamento, os parâmetros de altura de planta, diâmetro de colmo, massa da parte aérea da planta, massa da raiz, massa média da espiga, quantidade de espigas produzidas por planta e produtividade $\left(\mathrm{kg} \mathrm{ha}^{-1}\right)$. Também foram obtidos os teores de amido, proteína, fibra bruta, matéria mineral, umidade e voláteis, FDA, FDN e matéria seca da silagem de milho a partir de três repetições por tratamento. O experimento foi conduzido em delineamento inteiramente casualizado e os resultados submetidos ao teste de Tukey, ao nível de 5\% de probabilidade de erro. O uso de inoculante proporcionou maior altura de plantas, redução da massa de raiz e dos teores de amido e proteína da silagem. Os demais parâmetros analisados não foram alterados pela inoculação das sementes com $A$. brasilense.
\end{abstract}

Palavras-chave: Bactérias diazotróficas; Bactérias promotoras de crescimento; Zea mays L.

\begin{abstract}
Nitrogen fertilization plays a fundamental role in determining the productivity and profitability of the corn crop. Azospirillum genus has the ability, when associated with grasses, to fix atmospheric nitrogen, assist in the solubilization of inorganic phosphate and provide growth regulators that contribute to plant growth. This work aimed to evaluate the effect of using inoculation with Azospirillum brasilense on corn seeds grown for silage production in Santana do Livramento, RS. The treatments consisted of comparing corn plants for the production of silage with and without inoculation in the sowing of the strains AbV5 and AbV6 of Azospirillum brasilense, in the concentration of $2 \times 10^{8} \mathrm{CFU}$ $\mathrm{ml}^{-1}$. The parameters of plant height, stem diameter, mass of the aerial part of the plant, mass of the root, average mass of the ear, quantity of ears produced per plant and productivity were analyzed from 20 replicates per treatment. The contents of starch, protein, crude fiber, mineral matter, moisture and volatiles, ADF, NDF and dry matter of corn silage were also obtained from three replicates per treatment. The experiment was conducted in a completely randomized design. The results were submitted to the Tukey test, at the level of 5\% probability of error. The use of inoculant provided higher plant height and reduced root mass and starch and silage protein contents. The other parameters analyzed were not altered by inoculating the seeds with A. brasilense.
\end{abstract}

Keywords: Diazotrophic bacteria; Growth-promoting bacteria; Zea mays L.

\section{Resumen}

La fertilización con nitrógeno juega un papel fundamental en la determinación de la productividad y rentabilidad del cultivo de maíz. El género Azospirillum tiene la capacidad, cuando se asocia con pastos, para fijar nitrógeno atmosférico, ayudar en la solubilización del fosfato inorgánico y proporcionar reguladores de crecimiento que contribuyen al 
crecimiento de las plantas. Este trabajo tuvo como objetivo evaluar el efecto de la inoculación de Azospirillum brasilense en semillas de maíz cultivadas para ensilaje en Santana do Livramento, RS. Los tratamientos consistieron en comparar plantas de maíz para la producción de ensilaje con y sin inoculación en la siembra de cepas AbV5 y AbV6 de Azospirillum brasilense, a una concentración de $2 \times 10^{8} \mathrm{UFC} \mathrm{ml}^{-1}$. Los parámetros de altura de la planta, diámetro del tallo, parte aérea de la planta, masa radical, masa promedio de mazorcas, número de mazorcas producidas por planta y productividad se analizaron a partir de 20 repeticiones por tratamiento. Los contenidos de almidón, proteína, fibra cruda, materia mineral, humedad y volátiles, FDA, NDF y materia seca del ensilado de maíz también se obtuvieron a partir de tres réplicas por tratamiento. El experimento se realizó en un diseño completamente al azar y los resultados se sometieron a la prueba de Tukey, a un nivel de 5\% de probabilidad de error. El uso de inoculante proporcionó mayor altura a la planta y redujo la masa de raíces y el contenido de almidón y proteína en el ensilaje. Los demás parámetros analizados no fueron alterados por la inoculación de semillas con A. brasilense.

Palabras clave: Bacterias diazotróficas; Bacterias promotoras del crecimiento; Zea mays L.

\section{Introdução}

O milho pertence à família Poaceae, subfamília Panicoideae, tribo Maydeae e nome botânico Zea mays L. (Barbosa, 1983). Segundo Barros et al., (2014), o milho se originou do teosinto (Zea mays subsp. mexicana (Schrad.) Iltis). A cultura do milho é cultivada há mais de 8.000 mil anos em diversos países devido a sua boa adaptabilidade e aos seus variados genótipos, o que permite a sua produção em regiões de climas tropicais a temperados. Segundo Ponciano et al. (2003), o milho pode ser usado de forma in natura como forragem e ração no que se refere à alimentação animal. Conforme Emygdio et al. (2013), a produtividade média obtida no RS é de $3.000 \mathrm{~kg} \mathrm{ha}^{-1}$. Conforme o levantamento anual do acompanhamento da safra 2016/2017 realizado pela Emater/RS-Ascar, houve um incremento de 9,35\% na área cultivada, superando os 816 mil hectares (Rosa, 2017).

Segundo a FEE (2019), em 2018 foram produzidas 8.225 toneladas de milho no município de Santana do Livramento/RS, mantendo nos últimos três anos a média de produção. O município é caracterizado pela bacia leiteira formada por pequenos produtores familiares que realizam o plantio da cultura destinada à produção de silagem, a fim de suprir a necessidade de suplementação animal na época do vazio forrageiro (Silva, et al., 2019). Segundo Cotrim (2014), os motivos que levam os produtores leiteiros a optarem pela silagem de milho são a ampla oferta de híbridos no mercado, relativo baixo custo de produção e alta produtividade, a automação durante o processo de produção e a aceitação pelos animais, sendo o principal suplemento volumoso para os rebanhos leiteiros.

Dartora et al. (2013) afirmam que em solos com baixa fertilidade natural e deficiência de nitrogênio pode ser constatada a redução da produtividade do milho, bem como na maioria dos solos brasileiros que possuem baixa disponibilidade de nitrogênio. Além disso, apenas 50\% do nitrogênio aplicado nos solos são aproveitados pelas plantas, sendo o restante perdido em outros processos, tais como, a lixiviação e a volatilização. A adubação nitrogenada tem papel fundamental na determinação da produtividade e rentabilidade da cultura do milho. Dessa forma, é recomendável que a adubação nitrogenada atenda às necessidades da cultura agrícola, evite efeitos negativos do excesso de nitrato nos mananciais e que não seja onerosa para os produtores (Cantarella et al., 2004; Feitosa et al., 2021).

Na natureza existem alguns microrganismos capazes de colonizar a superfície das raízes, rizosfera, filosfera e os tecidos internos das plantas, dentre os quais as bactérias diazotróficas ou fixadoras de nitrogênio atmosférico, que possuem a capacidade de se associar às plantas em diferentes graus, podendo ser classificadas como bactérias associativas, endofíticas e/ou simbióticas (Hungria et al., 2007; Almeida et al., 2021; Silva et al., 2022). Dentre esses microrganismos, existem aqueles que são capazes de produzir reguladores de crescimento, como auxinas e giberelinas, sendo denominados também como Bactérias Promotoras de Crescimento em Plantas (BPCPs) por influenciarem no desenvolvimento e desempenho produtivo vegetal, bem como auxiliarem na absorção de água e nutrientes (Davison, 1888; Peoples et al., 1995; Silva et al., 2022).

Alguns exemplos de BPCPs são aquelas pertencentes aos gêneros Azospirillum, Rhizobium, Bradyrhizobium, Agrobactetirium e Gluconacetobacter. Esses gêneros são formados por bactérias gram-negativas de vida livre, com metabolismo de carbono e nitrogênio de grande versatilidade. O gênero Azospirillum possui a capacidade, quando associado com as gramíneas, 
de fixar o nitrogênio atmosférico e auxiliar com a solubilização do fosfato inorgânico, além de estar amplamente presente nos solos tropicais e subtropicais (Elmerich \& Newton, 2007; Huergo et Al., 2008, Almeida et al., 2021). Segundo Cantarella (2007), esses organismos assimilam o nitrogênio atmosférico e o transformam $\mathrm{em} \mathrm{NH}_{3}$, sendo responsáveis pela fixação biológica através do complexo enzimático nitrogenase. O processo de fixação biológica de nitrogênio consiste no segundo processo biológico das plantas de maior importância, atrás somente da fotossíntese.

O nitrogênio atua no metabolismo vegetal, pois participa diretamente na biossíntese de proteínas e clorofila, bem como no desenvolvimento inicial da planta (Andrade et al., 2003). Entretanto, a utilização de fertilizantes a base de amônio e ureia acaba ocasionando a acidificação do solo, principalmente com o aumento das doses no sistema de produção (Caires et al., 2015), onerando a produção e potencializando impactos ambientais (Fernandes et al., 2007).

Conforme Bartchechen et al. (2010), a principal barreira para a utilização de Azospirillum em larga escala tem sido a inconsistência dos resultados apresentados nos estudos. Essas variações têm sido associadas à diversidade genética das distintas cultivares, condições edafoclimáticas e metodologias utilizadas nas pesquisas.

Bashan et al. (2010) relataram maior desenvolvimento das raízes, absorção da água e minerais e uma maior tolerância ao estresse em relação à seca e à salinidade como resultados advindos da inoculação com Azospirillum brasilense. Já Correa et al. (2008) apontaram que com o aumento do crescimento radicular e nutrição pela prática da inoculação com o A. brasilense, as plantas desenvolvem uma maior tolerância aos agentes patogênicos.

Sales et al (2021) observaram, na inoculação das sementes de arroz com A. brasilense somados a $50 \%$ da dose de $\mathrm{N}$ recomendada, houve o incremento em altura de plantas, número de panículas e produtividade de grãos. Rampim (2021) não verificaram diferenças entre os tratamentos na primeira safra de milho, mesmo com doses superiores ao recomendado de inoculante. $\mathrm{O}$ maior desenvolvimento radicular das mudas foi obtido apenas a partir da reinoculação por duas safras seguidas, contudo foi restringido o desenvolvimento da parte aérea das plantas de milho.

Na pesquisa realizada por Novakowiski et al. (2011), foi avaliada a associação da adubação nitrogenada na pastagem de inverno (azevém e aveia preta) e a inoculação de A. brasilense no milho. Concluíram que nesse sistema de produção existe efeito residual do nitrogênio aplicado na pastagem sobre a cultura do milho, bem como o aumento da produtividade do milho pela inoculação. Para Dartora et al. (2013), ao avaliarem a resposta de inoculação de A. brasilense e H. seropedicae em relação à adubação nitrogenada no milho, verificaram que a adubação nitrogenada favoreceu o desenvolvimento da cultura. A inoculação dos microrganismos proporcionou um aumento de $12 \%$ na matéria seca da parte aérea e de $7 \%$ na produtividade.

Conforme Araújo et al. (2014), a inoculação com A. brasilense no milho aumentou o número e a massa das espigas comerciais empalhadas. Além disso, a combinação de inoculação e adubação nitrogenada aumentou em aproximadamente $30 \%$ a produção de espigas. Já no experimento conduzido por Dias et al. (2018), a inoculação com A. brasilense promoveu o aumento da produtividade e do teor de óleo nos grãos. Assim, o A. brasilense tem se mostrado como uma alternativa para complementar o fornecimento do nitrogênio para o milho (Araújo et al., 2015). Essa interação tem possibilitado a redução na aplicação de fertilizantes na cultura e a redução nos custos de produção, bem como proporcionado menor contaminação ambiental (Hungria et al., 2010). A partir do exposto e da necessidade de pesquisas, o presente trabalho teve como objetivo avaliar o efeito da inoculação de Azospirillum brasilense nas sementes de milho cultivado para a produção de silagem em Santana do Livramento, RS.

\section{Metodologia}

O experimento foi conduzido na área rural de Santana do Livramento - RS, no assentamento São Leopoldo, situado

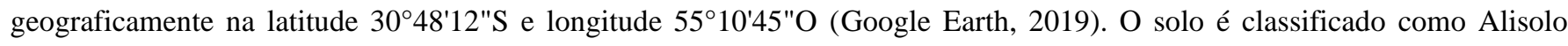
Hipocrômico, tendo por características ser medianamente profundo a profundo, com horizonte B podendo variar de textural a 
nítico. Caracterizado como solo profundo e bem drenado, sendo o horizonte A, $56 \mathrm{~cm}$, de areia franca espessa com transição clara para o horizonte B, de $200 \mathrm{~cm}$, predominante de argila. Quanto a parte química, este solo é ácido, com baixa Capacidade de Troca de Cátions (CTC), com teores de médio abaixo para K, Ca, Mg, e P e baixo teor de carbono orgânico no horizonte A, podendo chegar a média no horizonte B. É caracterizado como limitante quanto a fertilidade natural, apresenta alta susceptibilidade a erosão e com maior predisposição à ocorrência de deficiência hídrica às plantas pelos $100 \mathrm{~cm}$ de profundidade de solo arenoso (Klamt et al., 1995; Santos et al., 2018). É caracterizada como de clima subtropical úmido (CFA). Apresenta o mês mais frio com média acima de $3{ }^{\circ} \mathrm{C}$ e no mês mais quente com temperatura superior a $22^{\circ} \mathrm{C}$. A precipitação é abundante e bem distribuída ao longo de todo o ano (Köppen et al., 1928).

Os tratamentos consistiram em: T1 - inoculação das sementes e T2 - testemunha, sem inoculação das sementes por

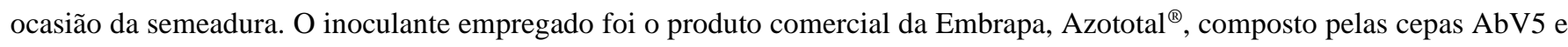
AbV6 da bactéria Azospirillum brasilense, na concentração de $2 \times 10^{8} \mathrm{UFC} \mathrm{m}{ }^{-1}$ e densidade de $1,00 \mathrm{~g} \mathrm{~cm}^{-3}$, aplicados manualmente em um tanque de plástico, de forma homogênea nas sementes no volume de $100 \mathrm{ml}$ de inoculante para cada 60.000 sementes e posteriormente foi realizada a semeadura.

A área total de plantio foi de 4,00 ha de milho, sendo uma gleba de 0,38 ha divididos em 0,19 ha destinados aos tratamentos com e sem inoculação. No dia 14/12/2019 foi realizada a semeadura e adubação com o auxílio de semeadoraadubadora Semeato (modelo PHS 125, com 03 linhas) sob sistema de plantio direto. Foi realizada adubação de base de $200 \mathrm{~kg}$ $\mathrm{ha}^{-1}$ de NPK (5-20-20) e $180 \mathrm{~kg} \mathrm{ha}^{-1}$ de adubo orgânico a base de cama de aviário (3-3-2) de acordo com as recomendações da Sociedade Brasileira de Ciência do Solo (2016).

As sementes de milho híbrido utilizadas foram da variedade 20A78PW $\left(\right.$ Morgan $\left.^{\circledR}\right)$, de ciclo superprecoce. Esse genótipo é resistente ao herbicida glifosato e com tecnologia $\mathrm{BT}^{\circledR}$ (Bacillus thuringiensis) de proteção contra insetos. A semeadura foi realizada na densidade de 8,8 grãos $\mathrm{m}^{-2}$, sendo a sua distribuição no espaçamento entre as plantas de $12,5 \mathrm{~cm}$ e entrelinhas de $90,0 \mathrm{~cm}$, o que equivale a uma densidade de plantio de 88.000 plantas ha $^{-1}$ (Silva et al., 2021). A área escolhida para o experimento tem sido utilizada para a semeadura do milho para a produção de silagem no verão há 15 anos, ficando em pousio entre os cultivos do milho no verão. No dia 01/12/2019, antes da semeadura, foi realizada a primeira aplicação de herbicidas para o controle de plantas espontâneas. O volume de calda utilizado na pulverização foi de $115 \mathrm{~L} \mathrm{ha}^{-1} \mathrm{e}$ as concentrações dos produtos comerciais adotadas foram de 1,7 $\mathrm{L} \mathrm{ha}^{-1} \mathrm{de}$ 2,4-D (sal de dimetilamina de (2,4-dichlorophenoxy) acetic acid) e $2 \mathrm{~kg}$ ha${ }^{1}$ de glifosato (sal isopropilamina de $\mathrm{N}$ - (phosphonomethyl) glicine).

Foram realizadas 20 repetições por tratamento. Cada repetição foi composta por três plantas de fileiras de semeadura lindeiras, coletadas a cada $7 \mathrm{~m}$. Antes de proceder a coleta das plantas, a altura de planta, com auxílio de fita métrica, obtida por meio da medição entre a superfície do solo até a inserção do pendão. $O$ diâmetro do colmo foi determinado a $10 \mathrm{~cm}$ da superfície do solo, com o auxílio de uma trena (Lopes, 2016; Gomes, 2019).

Após a coleta das plantas, foram realizadas as análises de massa da parte aérea da planta, massa da raiz e massa da espiga com o auxílio de uma balança digital. O número de espigas produzidas por planta também foi contabilizado e, juntamente com a densidade de plantas no momento da colheita, utilizado para determinar a produtividade. Para a análise de massa de raiz, foi realizado um corte com profundidade de um metro, retirado o excesso de solo e então pesadas individualmente. Já para a massa de espiga foram retiradas das plantas as espigas com palha e pesadas individualmente (Gomes, 2019).

A parte aérea das plantas e as espigas foram trituradas separadamente. Posteriormente foram alocadas em sacos individuais de polietileno de baixa densidade (PEBD) transparente de 150 micras. Esses sacos foram colocados em sacos de ráfia e acondicionados em um tambor de plástico azul coberto por saco preto, até o dia 26/05/2020, totalizando 48 dias em fermentação.

Os sacos foram abertos e a silagem de cada tratamento homogeneizada para a coleta de amostras de $50 \mathrm{~g}$, sendo 
utilizadas três repetições por tratamento. No mesmo dia da coleta, as amostras foram enviadas ao laboratório da empresa de nutrição Languiru $^{\circledR}$ para a realização da análise bromatológica. Foram determinados os teores de amido, proteína, fibra bruta, matéria mineral, umidade e voláteis, fibra em detergente ácido (FDA), fibra em detergente neutro (FDN) e matéria seca da silagem de milho conforme o método reconhecido pela "Association of Official Analytical Chemists" (AOAC) e aprovado oficialmente pelo Ministério da Agricultura (Ferrarini, 2004).

$\mathrm{O}$ experimento foi implantado em Delineamento Inteiramente Casualizado (DIC). Os resultados foram submetidos à análise de variância e a comparação das médias foi realizada pelo teste de Tukey, ao nível de 5\% de probabilidade de erro.

\section{Resultados e Discussão}

Na Tabela 1 estão dispostos os dados climáticos concedidos pelo INMET de acordo com cada período fenológico estimado durante o ciclo de desenvolvimento do experimento. A semeadura foi realizada no dia 14/12/2019, o período I - da germinação à emergência ocorreu do dia 14/12/2019 até 08/01/2020 (25 dias); o período II - de crescimento e desenvolvimento do dia 09/01/2020 até 12/02/2020 (34 dias); o período III - do florescimento ao enchimento de grãos do dia 13/02/2020 até o 23/03/2020 (39 dias); e o período IV - da maturação fisiológica até a colheita do dia 24/03/2020 até 08/04/2020 (15 dias).

Tabela 1- Condições térmicas e hídricas em distintos períodos fenológicos para a cultura do milho produzido para silagem em Santana do Livramento - RS, safra 2019/2020.

\begin{tabular}{c|c|c|c|c}
\hline \multirow{2}{*}{ Período } & \multicolumn{3}{|c|}{ Temperatura do ar $\left(^{\mathbf{0}} \mathbf{C}\right)$} & $\begin{array}{c}\text { Precipitação pluvial } \\
\text { (mm) }\end{array}$ \\
\cline { 2 - 5 } & Mínima & Média & Máxima & 83,4 \\
\hline I & 11,6 & 23,0 & 38,4 & 99,2 \\
\hline II & 9,3 & 23,6 & 34,6 & 102,2 \\
\hline III & 9,3 & 22,4 & 37,9 & 6,6 \\
\hline
\end{tabular}

Períodos fenológicos: Da germinação à emergência (I) 25 dias, de crescimento/desenvolvimento (II) 34 dias, do florescimento ao enchimento de grãos (III) 39 dias e da maturação fisiológica até a colheita (IV) 15 dias. Fonte: INMET (2020).

Tendo em vista que esse experimento não utilizou irrigação e a precipitação pluvial foi inferior à demandada pela cultura (Tabela 1), sua capacidade de desenvolvimento e produção não ocorreu nas condições mais adequadas para a cultura. A reduzida ocorrência de precipitação pluvial nos períodos fenológicos III e IV também foi inferior à normal climatológica para os meses de março e abril em Santana do Livramento.

As temperaturas mínimas foram muito inferiores às recomendadas por Landau et al. (2016), $21{ }^{\circ} \mathrm{C}$ a $25^{\circ} \mathrm{C}$, não alcançando $12^{\circ} \mathrm{C}$. Enquanto as máximas recomendadas $\left(30^{\circ} \mathrm{C}\right.$ a $\left.35^{\circ} \mathrm{C}\right)$, sendo nos períodos fenológicos I e III superiores, com $38,4{ }^{\circ} \mathrm{C}$ e $37,9{ }^{\circ} \mathrm{C}$ respectivamente, e nos períodos fenológicos II e IV de acordo com o recomendado, de $34,6{ }^{\circ} \mathrm{C}$ e $31,6{ }^{\circ} \mathrm{C}$ respectivamente. As temperaturas médias foram similares às observadas na normal climatológica dos últimos 10 anos e estiveram de acordo com a recomendação para a cultura (Landau et al., 2016).

Os dados de altura de planta e diâmetro de colmo de milho com e sem inoculação de A. brasilense na semeadura estão dispostos na Tabela 2. 
Tabela 2 - Altura média de planta $(\mathrm{cm})$ e diâmetro médio do colmo $(\mathrm{cm})$ do milho produzido para silagem, com e sem inoculação de Azospirillum brasilense na semeadura em Santana do Livramento - RS, safra 2019/2020.

\begin{tabular}{c|c|c}
\hline Tratamento & Altura de planta (cm) & Diâmetro de colmo (cm) \\
\hline Com inoculação & 134,39 a & $6,28 \mathrm{~ns}$ \\
\hline Sem inoculação & 119,56 b & $12,47 \%$ \\
\hline CV $(\%)$ & $10,71 \%$ & 60 \\
\hline
\end{tabular}

Médias seguidas por letras distintas na mesma coluna diferem estatisticamente entre si pelo teste de Tukey ao nível de 5\% de probabilidade de erro. ns: não significativo. Fonte: Autores (2020).

A utilização de inoculante na semeadura do milho ocasionou maior altura de planta. No entanto, não houve diferença entre o diâmetro de colmo das plantas de milho com e sem inoculação.

Segundo Mendonça et al. (2006), as bactérias A. brasilense tem a capacidade de colonizar primeiramente as raízes, seguidas pelos colmos e por último as folhas. Pode não ter ocorrido a colonização de forma expressiva nos colmos, não diferindo quanto ao diâmetro das plantas testemunhas. Corroborado, Gaviraghi (2021) obteve maior diâmetro de colmo em plantas inoculadas com A. brasilense e o emprego de metade das doses recomendadas de adubação nitrogenada e cama de aviário.

Junior et al. (2020) verificaram aumento de altura de plantas e diâmetro do colmo das plantas de milho quando realizadas adubações nitrogenadas em diferentes doses, sem que o uso de inoculante influenciasse nesses parâmetros. Silva et al (2021) também não observaram variação na altura de plantas e diâmetro do colmo ao testarem a associação de quatro doses distintas de adubação nitrogenada em conjunto com a inoculação com A. brasilense em experimento com milho. Vendruscolo et al. (2020), em experimento conduzido em solo latossolo vermelho com adubação de cobertura e nitrogenada e aplicações isoladas de $A$. brasilense e tiamina no município de Goiânia, também não verificaram respostas significativas quanto à altura de plantas e diâmetro do colmo no milho doce.

Lopes (2016) comparou a inoculação de A. brasilense nas sementes de milho Velox TL ${ }^{\circledR}$ (ciclo superprecoce) com a inoculação realizada no sulco de modo mecanizado em Cruzeiro do Sul/RS na safra 2015/2016. Naquelas condições, independentemente do método de inoculação, Azospirillum brasilense também proporcionou maior altura do milho plantado, bem como não houve influência no diâmetro do colmo, corroborando com os resultados do presente experimento em que se realizou a inoculação manual das sementes e logo em seguida se realizou a semeadura.

Fachinelli (2017), em experimento conduzido em condições de solo e inoculação semelhantes às do presente trabalho, testou diferentes espaçamentos de plantio e verificou efeito significativo das BPCP no diâmetro de colmo para o espaçamento de $90 \mathrm{~cm}$. De acordo com Batistela \& Barbosa (2017), em pesquisa realizada no período de maio a junho do ano de 2016 em Ourinhos - SP para comparar o desempenho de diferentes híbridos de milho (ciclos superprecoces) submetidos à inoculação de sementes com Azospirillum brasilense (dose de $100 \mathrm{~mL} \mathrm{ha}^{-1}$ ), concluíram que a inoculação das sementes não apresentou influência nos híbridos testados para os parâmetros de altura de planta e diâmetro de colmo devido às interferências de fatores edafoclimáticos.

Jales et al. (2021) não verificaram interação entre diferentes disponibilidades hídricas com o uso de inoculação com Azospirillum brasilense, condição alterada apenas para adubação nitrogenada. Oliveira et al. (2021b) não observaram influência pela inoculação com A. brasilense e pela adubação nitrogenada fornecida no consórcio com soja e no monocultivo do milho para silagem em índice de clorofila foliar, teores foliares (N, P, K, Ca, Mg, S, Fe, Mn, Zn e B), altura de planta, diâmetro de colmo e densidade de plantas.

Os dados de massa média fresca de planta e de raiz do milho com e sem inoculação de $A$. brasilense na semeadura estão dispostos na Tabela 3. 
Tabela 3 - Massa média fresca da parte aérea $(\mathrm{g})$ e da raiz $(\mathrm{g})$ de milho produzido para silagem, com e sem inoculação de Azospirillum brasilense na semeadura em Santana do Livramento - RS, safra 2019/2020.

\begin{tabular}{c|c|c}
\hline Tratamento & Massa de planta (g) & Massa de raiz (g) \\
\hline Com inoculação & $646,61 \mathrm{~ns}$ & $148,15 \quad \mathrm{~b}$ \\
\hline Sem inoculação & 624,90 & $241,77 \mathrm{a}$ \\
\hline CV $(\%)$ & $26,74 \%$ & $50,75 \%$ \\
\hline
\end{tabular}

Médias seguidas por letras distintas na mesma coluna diferem estatisticamente entre si pelo teste de Tukey ao nível de 5\% de probabilidade. ns: não significativo. Fonte: Autores (2020).

A utilização de inoculante na semeadura do milho para produção de silagem não afetou a massa média da parte aérea da planta. Gaviraghi (2021) em seu experimento associando doses de N, cama de aviário e A. brasiliense, não constatou influência da inoculação nos mesmos parâmetros. Rampim (2021) obteve maior desenvolvimento radicular das mudas de milho, quando reinoculadas em safras seguidas, com A. brasilense, porém foi identificada a redução do desenvolvimento da parte aérea.

As condições térmicas e de escassez hídrica ocorridas durante o ciclo da cultura (Tabela 1) podem ter contribuído para não ter havido melhor desempenho das plantas submetidas à inoculação na semeadura. Conforme Barros \& Calado (2014), o estresse hídrico reduz a capacidade normal de absorção de nutrientes provindos do solo e pode influenciar no desenvolvimento das plantas também pelo fechamento estomático e redução da fotossíntese líquida.

Entretanto, aquelas plantas que se desenvolveram sem a influência do inoculante apresentaram maior massa média fresca de raiz. Esse resultado pode ser um indicativo de que as plantas testemunhas necessitaram de maior crescimento e atividade radicular para prover de nutrientes e água e manter o mesmo acúmulo de massa úmida da parte aérea quando comparadas às plantas oriundas de semeadura com a inoculação de A. brasilense, como observado por Jales et al (2021).

De acordo com Barber et al. (1988), a temperatura e a disponibilidade hídrica interferem no desenvolvimento do sistema radicular e na absorção de nutrientes do milho, que em situações de estresse hídrico severo somente deixa de se desenvolver apenas no ponto de murcha permanente. A precipitação pluvial acumulada nos meses de dezembro a fevereiro totalizou 182,6 $\mathrm{mm}$, superando os $150 \mathrm{~mm}$ necessários nos períodos fenológicos I e II, enquanto nos períodos fenológicos III e IV, nos meses de março e abril, houve o acúmulo de 108,8 mm, sendo inferiores aos $800 \mathrm{~mm}$ recomendados como ideais (Tabela 1). Os valores de temperaturas mínimas e máximas em todos os períodos fenológicos não foram adequados, no entanto as temperaturas médias atenderam às necessidades da cultura. Com tais variações de temperatura e estresse hídrico nos estágios finais, a absorção de nutrientes e desenvolvimento das raízes são diretamente afetadas.

Lima (2018) e Vendruscolo et al. (2020) não observaram alterações na produção de massa fresca e seca de milho pelo emprego de inoculante com A. brasilense, atribuindo que fatores como estresse hídrico afetaram negativamente os efeitos do uso de inoculante. Corroborando, Jales et al. (2021) em experimento com restrição hídrica e inoculação com A. brasiliense e doses diferentes de $\mathrm{N}$ verificaram que o estresse hídrico promoveu maior comprimento de raiz. Miotti (2021) constataram maior tolerância de plantas de milho submetidas ao estresse salino com o uso do inoculante.

Os dados de massa média da espiga, quantidade de espigas produzidas por planta e produtividade da lavoura de milho com e sem inoculação de $A$. brasilense na semeadura estão dispostos na Tabela 4. 
Tabela 4 - Massa média da espiga (g), quantidade de espigas produzidas por planta ( $\mathrm{n}^{\circ}$ ) e produtividade (kg) de lavoura de milho produzida para silagem, com e sem inoculação de Azospirillum brasilense na semeadura em Santana do Livramento - RS, safra $2019 / 2020$.

\begin{tabular}{c|c|c|c}
\hline Tratamento & Massa média da espiga $(\mathbf{g})$ & Quantidade de espigas por planta (no) & Produtividade \\
\hline \multicolumn{5}{|c|}{$\left(\mathbf{k g ~ h a}^{\mathbf{- 1}}\right)$} \\
\hline Com inoculação & $277,18 \mathrm{~ns}$ & $1,22 \mathrm{~ns}$ & $14248 \mathrm{~ns}$ \\
\hline Sem inoculação & 249,75 & 1,17 & 12456 \\
\hline CV $(\%)$ & 19,61 & 25,14 & 29,30 \\
\hline
\end{tabular}

ns: não significativo. Fonte: Autores (2020).

A utilização de inoculante na semeadura de milho não influenciou na massa média fresca de espiga, quantidade de espigas produzidas por planta e produtividade da lavoura no presente experimento. Spolaor et al. (2016) e Gaviraghi (2021) também não verificaram influência na produtividade de milho em decorrência de inoculação com A. brasiliense das mesmas estirpes Abv5 e Abv6 utilizadas no presente experimento, ou mesmo com diferentes doses de adubação nitrogenada de cobertura em latossolo vermelho.

Amorim et al. (2021) não verificaram diferença estatística quanto ao parâmetro produtividade, contudo, evidenciou-se um incremento de três sacas de milho (sacas de $60 \mathrm{~kg}$ ) entre os tratamentos em relação à testemunha. O presente trabalho também não constatou diferença estatística quanto aos parâmetros produtivos de massa média da espiga, quantidade de espigas produzidas por planta e produtividade de lavoura de milho produzida para silagem.

Junior et al. (2020) não observaram influencia no uso de inoculante nos parâmetros número de fileiras por espiga, número de grãos por fileira, número de grãos por espiga, massa de 1000 grãos e produtividade. Silva et al (2021) associando quatro doses diferentes de adubação nitrogenada e a inoculação com A. brasilense também não verificaram influência na produção do milho. Barros (2019), em experimento realizado no município de Arapiraca - AL, ao avaliar a associação de fontes de $\mathrm{N}$ com inoculação de $A$. brasilense, também constatou que a inoculação das sementes de milho doce com a BPCP não interferiu no rendimento de grãos.

Vorpagel (2012) também não observou alteração no rendimento de grãos, massa de mil grãos, massa de grãos da espiga, número de fileiras por espiga e número de grãos por fileira pelo emprego de A. brasilense no Noroeste do RS (Augusto Pestana), sendo observado maior rendimento de grãos mediante o aumento da massa média de grãos em decorrência do uso isolado da dose completa de nitrogênio em cobertura. No presente experimento também não se observou alteração no resultado da produção de massa média fresca da parte aérea e dos componentes de rendimento de grãos, avaliados pela massa média fresca de espiga, quantidade de espigas produzidas por planta e produtividade estimada da lavoura.

Vendruscolo et al. (2020) observaram que aplicações isoladas de A. brasilense e tiamina não obtiveram respostas significativas quanto à produtividade de matéria seca e fresca das espigas do milho doce. Por outro lado, Fachinelli (2017), no Mato Grosso do Sul (Vicentina), verificou que o inoculante propiciou o aumento do número de espigas produzidas por planta em experimento conduzido nas mesmas condições de solo (areia quartzosa álica). Duarte et al. (2021), ao testarem a inoculação de A. brasilense na semeadura do milho em condição de solo arenoso como no presente experimento, também não obtiveram interferência nos parâmetros produtivos.

Os parâmetros da análise bromatológica das silagens produzidas com e sem inoculação de A. brasilense na semeadura do milho estão dispostos na Tabela 5. 
Tabela 5 - Teores de amido - Am (\%), proteína - Prot (\%), fibra bruta - FB (\%), matéria mineral - MM (\%), umidade e voláteis - Um e Vol (\%), Fibra Detergente Ácido - FDA (\%), Fibra Detergente Neutro - FDN (\%) e matéria seca - MS (\%) de silagem de milho produzida com e sem inoculação de Azospirillum brasilense.

\begin{tabular}{|c|c|c|c|c|c|c|c|c|}
\hline Tratamento & Am & Prot & FB & $\mathbf{M M}$ & Um e Vol & FDA & FDN & MS \\
\hline \multicolumn{9}{|c|}{$(\%)$} \\
\hline $\begin{array}{c}\text { Com } \\
\text { inoculação }\end{array}$ & $35,51 \mathrm{~b}$ & $7,10 \quad b$ & $19,75 \mathrm{~ns}$ & $5,50 \mathrm{~ns}$ & $65,76 \mathrm{~ns}$ & $24,96 \mathrm{~ns}$ & $40,52 \mathrm{~ns}$ & $34,24 \mathrm{~ns}$ \\
\hline $\begin{array}{c}\text { Sem } \\
\text { inoculação }\end{array}$ & $41,12 \mathrm{a}$ & $8,32 \mathrm{a}$ & 17,99 & 5,05 & 67,65 & 21,45 & 49,27 & 32,35 \\
\hline $\mathrm{CV}(\%)$ & 4,87 & 6,86 & 5,16 & 33,03 & 4,61 & 10,90 & 31,53 & 9,25 \\
\hline
\end{tabular}

Médias seguidas por letras distintas na mesma coluna diferem estatisticamente entre si pelo teste de Tukey ao nível de 5\% de probabilidade de erro. ns: não significativo. Fonte: Autores (2020).

A silagem produzida sem o uso de inoculante apresentou maiores teores de amido e proteína do que as plantas de milho inoculadas na semeadura. Os parâmetros de fibra bruta, matéria mineral, umidade e voláteis, FDA, FDN e matéria seca não foram alterados pela inoculação em relação à testemunha sem o uso de A. brasilense.

Galeano et al. (2019) realizaram um experimento in vitro, onde extraíram A. brasilense de estirpes AbV5 e AbV6 de duas gramíneas, Hymenachne amplexicaulis (Rudge) Nees (canarana) e Digitaria decumbens Stent. (capim pangola) e observaram maiores concentrações proteicas e incremento de matéria seca do que sem a realização de inoculação. Esses resultados divergem do presente experimento, em que o uso de inoculante comercial não alterou a composição da matéria seca da silagem. Em pesquisa realizada por Grunewald (2021), a inoculação de A. brasilense em plantas de milho não modificou a produtividade, a altura de plantas, altura de espigas, a massa verde, a massa seca. Vendruscolo et al. (2020) observaram que aplicações isoladas de $A$. brasilense não apresentaram influência nos teores de proteína bruta no milho doce, bem como para os parâmetros de altura de plantas, diâmetro de colmo e produtividade de matéria seca e fresca.

Silva et al. (2021) constatou que a inoculação aumenta a porcentagem de extrato etéreo da silagem e a massa de 1000 grãos, conforme se elevou a dose de nitrogênio em cobertura. Conforme Oliveira et al. (2021a), a adubação nitrogenada aplicada no milho inoculado e consorciado com a soja propiciou composição bromatológica, digestibilidade, pH, teores de energia e perfil de ácidos orgânicos característicos de silagem com qualidade adequada. Skonieski (2015), em experimento conduzido nos municípios de Erechim e Santa Maria na safra 2013/2014, testou diferentes níveis de adubação nitrogenada com e sem inoculação de dois híbridos de milho (AS1572 ${ }^{\circledR}$ e Defender ${ }^{\circledR}$, ambos de ciclo precoce e híbridos com tecnologia BT $^{\circledR}$ ) para produção de silagem e grãos. Diferentemente do presente experimento, naquelas condições a inoculação com a BPCP ocasionou o aumento da produtividade de silagem e grãos, elevou a digestibilidade da matéria orgânica e reduziu a FDA da silagem.

Também contrastando com o ocorrido no presente experimento em que a área ficou em pousio entre os cultivos do milho, Bertoncell et al. (2017) testaram a influência de culturas de cobertura no inverno antecessoras ao cultivo do milho para a produção de silagem com e sem a inoculação de A. brasilense na semeadura no município de Santa Maria. Os autores verificaram que a inoculação aumentou a produtividade de grãos, porém sem influenciar no teor de proteína da silagem do milho. No entanto, a cobertura do solo no inverno com a cultura da aveia preta (Avena strigosa S.), cultivar moreninha, melhorou a qualidade bromatológica (massa seca, proteína bruta, FDA, FDN e cinza bruta) da silagem de milho produzida em sequência. 


\section{Considerações Finais}

Em condições convencionais de cultivo do milho ocorre a produção de plantas com maior massa fresca de raiz e silagem com maiores teores de amido e proteína do que a partir de plantas produzidas com a inoculação de sementes utilizando inoculante a base de Azospirillum brasilense. A inoculação ocasiona a produção de plantas com maior altura, sem alterar a produção de massa úmida da parte aérea, massa de espigas e a produção de espigas por planta em ano agrícola de estiagem nas condições edafoclimáticas de Santana do Livramento.

Estudos para determinar a relação equilibrada de adubação nitrogenada e o emprego de inoculante em distintas condições edafoclimáticas e com diferentes genótipos de milho se fazem necessários com o intuito de melhor compreensão da interação entre os fatores envolvidos para a promoção de sistemas mais sustentáveis de produção. Também se mostram promissores projetos de pesquisa que busquem o acompanhamento da mesma área para avaliar o efeito das reinoculações e seus impactos na otimização do uso de nitrogênio para as diferentes culturas agrícolas.

\section{Agradecimentos}

Os autores agradecem o apoio da Languiru ${ }^{\circledR}$ pela viabilização das análises bromatológicas.

\section{Referências}

Almeida, L. S., de Paiva Sobrinho, S., da Luz, P. B., Caldeira, D. S. A., de Oliveira, A. J., de Oliveira, T. C., ... \& da Silva, G. V. B. (2021). Uso de inoculante Azospirillum brasilense na produção de mudas de Tento Carolina. Research, Society and Development, 10(1), e4210111469-e4210111469.

Amorim, A. R. et al. (2020). Avaliação da eficiência da inoculação com azospirillum brasiliense em campo de produção de sementes de milho hibrido: um artigo original. Anais do $3^{\circ}$ Simpósio de TCC, das faculdades FINOM e Tecsoma. 13-29.

Andrade, A. C. et al. (2003). Adubação nitrogenada e potássica em capim-elefante (PennisetumpurpureumSchum.cv. Napier). Ciência e Agrotecnologia, Lavras, (Edição especial), 1643-51.

Araújo, E. O.; et al. (2015). Effect of nitrogen fertilization associated with inoculation of Azospirillum brasilense and Herbaspirillum seropedicae on corn. African Journal of Agricultural Research, Nairobi. 10(3), 137-45

Araújo, R. M.; et al. (2014). Resposta do milho verde à inoculação com Azospirillum brasilense e níveis de nitrogênio. Ciência Rural, 44(9), 1556-1560.

Barber, S.A.; et al. (1988). Efeitos da temperatura e da água no solo no crescimento radicular do milho. Planta e Solo, 111(2), 267-269.

Barbosa, J. V. A. (1983). Fisiologia do milho. In: empresa brasileira de assistência técnica e extensão rural, Embrater. Cultura do milho. Brasília: Embrater. 7 12 .

Barros, D.T.S, et al. (2019). Produção de milho doce sob fontes e doses de nitrogênio em associação à Azospirillum brasilense.

Barros, J. F. C. \& Calado, J. G. (2014). A cultura do milho. 52.

Bartchechen, A.; et al. (2010). Efeito da inoculação de Azospirillum brasilense na produtividade da cultura do milho (Zea mays L.). Campo Digital, Campo Mourão. 5(1), 56-59.

Bashan, Y \& Bashan, L. E (2010). How the plant growth-promoting bacterium Azospirillum promotes plant growth - a critical assessment. Advances in agronomy, $108,77-136$.

Batistela, L. H. L.; Barbosa, R. Z. (2017). Aplicação do enraizador (Azospirillum brasiliense) em diferentes híbridos de milho. Revista Científica Eletrônica de Agronomia, 31. ISSN: 1677-0293.

Bertoncelli, P; et al. (2017). O manejo de inverno e inoculação de sementes influenciam na produtividade e qualidade da silagem de milho sob sistema plantio direto. Revista Ceres, 64(5), 523-531. ISSN 2177-3491. Doi:10.1590/0034-737x201764050010.

Cantarella, H. (2007). Nitrogênio. In: Novais, R. F.; Alvarez V., V. H.; Barros, N. F.; Fontes, R. L. F.; Cantarutti, R. B.; Neves, J. C. L. (Ed.). Fertilidade do solo. Viçosa, MG, Sociedade Brasileira de Ciência do Solo, 375- 470.

Cantarella, H.; Duarte, A. P. (2004). Manejo da fertilidade do solo para a cultura do milho. In: Galvão, J. C. C. \& Miranda, G. V. Tecnologias de produção do milho. Viçosa, MG: Universidade Federal de Viçosa. 139-182.

Correa, O. S.; et al. (2008). Azospirillum brasilense-plant genotype interactions modify tomato response to bacterial diseases, and root and foliar microbial communities. In: Cassán, F. D.; Garcia de salamone, i. (ed.) Azospirillum sp.: cell physiology, plant interactions and agronomic research in Argentina. Argentina: Asociación Argentina de Microbiologia, 87-95. 
Cotrim, Décio (Org.). (2014). Desenvolvimento rural e agricultura familiar: produção acadêmica da Ascar. Porto Alegre, RS: Emater/RS-Ascar. Coleção Desenvolvimento Rural, 3. http://www.emater.tche.br/site/arquivos_pdf/teses//E_Book3.pdf.

Silva, C. J. L; et al. (2014). Análise multidimensional da sustentabilidade em sistemas produtivos de leite em Santana do Livramento, Rio Grande do Sul. Revista Verde de Agroecologia e Desenvolvimento Sustentável,14(4), 531-539.

Da Silva, D. F., de Melo Garcia, P. H., de Lima Santos, G. C., de Farias, I. M. S. C., de Pádua, G. V. G., Pereira, P. H. B., ... \& Cabral, A. M. D. (2021). Características morfológicas, melhoramento genético e densidade de plantio das culturas do sorgo e do milho: uma revisão. Research, Society and Development, 10(3), e12310313172-e12310313172.

Silva, V. A. M., Ferreira, J. S., Santos, R. K. A., Nascimento, C. C., Rodrigues, V. A., \& de Lima, M. C. D. (2022). Desempenho do clone AEC144 de Eucalipto inoculado com bactérias diazotróficas no Sudoeste da Bahia. Research, Society and Development, 11(2), e29211225589-e29211225589.

Dartora.; et al. (2013). Adubação nitrogenada associada à inoculação com Azospirillum brasilense e Herbaspirillum seropedicae na cultura do milho. Revista Brasileira de Engenharia Agrícola e Ambiental, Campina Grande, 17(10), 1023-1029. Doi:10.1590/S1415-43662013001000001.

Davison, J. (1988). Plant beneficial bacteria. Bio/Technology, 6, 282-286.

Souza Sales, L. Z., Garcia, N. F. S., Martins, J. T., de Souza Buzo, F., Garé, L. M., Rodrigues, R. A. F., \& Arf, O. (2021). Inoculação com Azospirillum brasilense e redução da adubação nitrogenada em arroz de terras altas. Research, Society and Development, 10(7), e9110716345-e9110716345.

Departamento de Pesquisas e Estudos Econômicos. (2017). Economia em dia. Bradesco. https://www.economiaemdia.com.br

Dias, V. C.; et al. (2018). Effects of seed inoculation with Azospirillum brasilense and nitrogen dose on oil content of corn grains. Revista de Agricultura, 93(3).

Dos Santos, H. G; et al. (2018). Sistema brasileiro de classificação de solos. Brasília, DF: Embrapa.

Duarte, J. P; et al. (2021). Inoculação de milho com inoculante à base de Azospirillum brasilense sob doses de nitrogênio em solo arenoso. Scientific Electronic Archives, 14(8).

Elmerich. C. \& Newton, W. E. (2007). Associative and eudoplrytic nitrogen-fíxing bactéria and cyauobacterial associatious. Dordrecht: Springer, 321(5).

Emygdio, B. M., et al. (2013). Recomendação de variedades de milho para o sul do Brasil. Embrapa Clima Temperado. Boletim de Pesquisa e Desenvolvimento, $1678-2518$

Fachinelli, R.; et al. (2017). Produtividade de milho safrinha com Azospirillum nas sementes em solo arenoso. In: Embrapa Agropecuária Oeste-Resumo em anais de congresso (ALICE). In: Seminário Nacional [De] Milho Safrinha, Cuiabá. Construindo sistemas de produção sustentáveis e rentáveis: anais. Sete Lagoas: Associação Brasileira de Milho e Sorgo, 14, 443-448.

FEE- Fundação de Economia e Estatística Siegfried Emanuel Heuser. Produção de milho no município de Santana do Livramento/RS. http://www.fee.rs.gov.br.

Feitosa, A. L. P. M., Siqueira, G. M., de Moura, E. G., Farias, F. F., \& Aguiar, A. D. C. F. (2021). Linkages among Soil Fertilization Regimes, Chemical Properties and Maize Grains Yield in Humid Tropic. Research, Society and Development, 10(16), e366101623558-e366101623558.

Fernandes, F. C. S. \& Libardi, P. L. (2007). Percentagem de recuperação de nitrogênio pelo milho, para diferentes doses e parcelamentos do fertilizante nitrogenado. Revista Brasileira de Milho e Sorgo, Sete Lagoas, 6(3),285-296.

Ferrarini, H. (2004). Determinação de teores nutricionais de milho por espectroscopia no infravermelho e calibração multivariada. Tese de Doutorado. Dissertação de Mestrado, DQ-UFPR.

Galeano, R. M. S.; et al. (2019). Desenvolvimento inicial e quantificação de proteínas do milho após inoculação com novas estirpes de Azospirillum brasilense. Journal of Neotropical Agriculture, 6(2), 95-99. Doi:10.32404/rean.v6i2.2613.

Gomes, G. P. (2019). Influência de gotejadores com saída de água tipo fenda e cilíndrica na intrusão radicular em irrigação subsuperficial na cultura do milho. http://hdl.handle.net/11449/190902.

Grunewald, G. A. V. (2021). Resposta do milho ao Azospirillum brasilense em diferentes sistemas de cultivo. f 34. Universidade Estadual de Paulista. Dissertação mestrado, (Genética e Melhoramento de Plantas) - FCAV.

Huergo, L.F.; et al. (20008). Regulation of nitrogen fixation in Azospirillum brasilense. In: Cassán, F.D.; Garcia De Salamone, I. Azospirillum sp.: cell physiology, plant interactions and agronomic research in Argentina. Argentina: Asociación Argentina de Microbiologia, 17-35.

Hungria, M.; et al. (2007). A importância do processo de fixação biológica do nitrogênio para a cultura da soja: componente essencial para a competitividade do produto brasileiro. Londrina: Embrapa Soja. Documentos, 283.

Hungria, M.; et al. (2010). Inoculation with selected strains of Azospirillum brasilense and A. lipoferum improves yields of maize and wheat in Brazil. Plant and Soil, Hague, 331(1/2), 413- 425 .

Jales, H. F.; et al. (2021). Morfofisiologia do milho inoculado com Azospirillum brasilense submetido à restrição hídrica e adubação nitrogenada. Embrapa Milho e Sorgo, Boletim de Pesquisa e Desenvolvimento (INFOTECA-E).

Júnior, N. B. et al. (2020). Parcelamento de nitrogênio e inoculação das sementes com Azospirillum brasilense na cultura do milho. Brazilian Journal of Development, 6(11), 89544-89663.

Klamt, E. (1995). Distribuição, classificação, características e limitações de solos de vinhedos experimentais de Bento Gonçalves, Pinheiro Machado e Sant'Ana do Livramento, RS, Brasil. EMBRAPA/CNPUV, 53. 
Research, Society and Development, v. 11, n. 3, e6611326165, 2022

(CC BY 4.0) | ISSN 2525-3409 | DOI: http://dx.doi.org/10.33448/rsd-v11i3.26165

Köppen, W. \& Geiger, R. (1928). Klimate der Erde. Gotha: Verlag Justus Perthes. Wallmap 150cmx200cm.

Landau, E. C.; et al. (2016). Árvore do conhecimento: relações com o clima. Embrapa Milho $e$ Sorgo. https://www.agencia.cnptia.embrapa.br/gestor/milho/arvore/CONTAG01_17_16820 0511157.html.

LIMA, C. S. (2020). Rendimento da cultura do milho em resposta à inoculação com Azospirillum brasilense associado às diferentes doses de nitrogênio e plantas de cobertura. 42. f. Trabalho de Conclusão de Curso de Graduação em Agronomia - Departamento de Estudos Agrários da Universidade Regional do Noroeste do Estado do Rio Grande do Sul.

Lopes, M. M. (2016). Pulverização dirigida no sulco e inoculação na semente de milho com Azospirillum brasilense. http://repositorio.ufsm.br/handle/1/13000.

Mendonça, M.; et al. (2006). Genotypic variability of maize for nitrogen accumulation and contribution of biological nitrogen fixation. Pesquisa Agropecuária Brasileira, 41(11), 1681-1685.

Miotti, F. (2021). Interação entre respostas antioxidantes e Azospirillum brasilense no milho cultivado sob estresse salino. f 43 . Trabalho de conclusão de curso (bacharelado em ciências agrarias), Universidade Estadual de Paulista - UNESP.

Novakowiski, J. H.; et al. (2011). Efeito residual da adubação nitrogenada e inoculação de Azospirillum brasilense na cultura do milho. Semina: Ciências Agrárias, Londrina, 32(1), 1687-1698.

Oliveira, J. F. A., Vieira, D. A., Leite, G. G., Pereira, L. S., Silva, J. N., \& Jakelaitis, A. J. (2021b). Manejo da adubação nitrogenada e da inoculação com Azospirillum brasilense no rendimento de silagem do consórcio milho-soja: Adubação no consórcio milho e soja. Revista Brasileira de Agropecuária Sustentável, 11(1), 280-289.

Oliveira, J. F. A; et al. (2021a). Qualidade da silagem do consórcio entre milho e soja manejado com inoculante Azospirillum brasilense e adubação nitrogenada. Revista Brasileira de Saúde e Produção Animal, 22.

Peoples, M. B.; et al. (1995). Biological nitrogen fixation: na efficient source of nitrogen for sustainable agricultural production. Plant and soil, 174(1-2), 3-28,

Ponciano, N. J.; et al. (2003). Entraves da comercialização à competitividade do milho brasileiro. Revista Paranaense de Desenvolvimento, 104, 23-40.

Rampim, L., Guimarães, V. F., Salla, F. H., da Costa, A. C. P. R., Inagaki, A. M., Bulegon, L. G., \& de França, R. (2020). Desenvolvimento inicial de plântulas de milho reinoculadas com bactérias diazotróficas. Research, Society and Development, 9(5), e24953109-e24953109.

Rosa, A. P. S. A.; et al. (2017). Indicações técnicas para o cultivo de milho e de sorgo no Rio Grande do Sul: safras 2017/2018 e 2018/2019. LXII Reunião Técnica Anual da Pesquisa do Milho; XLV Reunião Técnica Anual da Pesquisa do Sorgo, Sertão, RS, 17 a 19 de julho de 2017. - Brasília, DF: Embrapa, 209. ISBN: 978-85-7035-767-0.

Silva, D. C. et al. (2021). Avaliação da adubação nitrogenada associada à inoculação com bactérias Azospirillum brasilense na cultura do milho. Brazilian Journal of Development, 7(10), 99862-99881.

Skonieski, F.R.; et al. (2015). Inoculação de Azospirillum brasilense e doses de nitrogênio em milho para produção de silagem e grãos. Tese de Doutorado. Universidade Federal de Santa Maria. https://repositorio.ufsm.br/handle/1/4374.

Sociedade Brasileira de Ciência do Solo (2016). Manual de calagem e adubação para os Estados do Rio Grande do Sul e de Santa Catarina. Núcleo Regional Sul. Comissão de Química e Fertilidade do Solo - RS/SC. 376 p. ISBN: 978-85-66301-80-9.

Spolaor, L. T. I.; et al. (2016). Bactérias promotoras de crescimento associadas a adubação nitrogenada de cobertura no desempenho agronômico de milho pipoca. Bragantia, 75(1), 33-40. https://www.scielo.br/pdf/brag/2016nahead/pt_0006-8705-brag-1678-4499330.pdf.

Vendruscolo, P. E.; et al. (2020). Productividad e indicadores económicos de ensilaje de maíz dulce tratado con bacterias diazotróficas y tiamina. Revista Colombiana de Ciencia Animal - RECIA, 12(1), 738.

VorpageL, A. G. (2012). Inoculação de Azospirillum, isolado e associado à bioestimulante, em milho, no Noroeste do RS. 56. f. Trabalho de Conclusão de Curso de Graduação em Agronomia (Universidade Regional do Noroeste do Estado do Rio Grande do Sul). http://hdl.handle.net/123456789/643. 